\title{
Lycopene isomerisation takes place within enterocytes during absorption in human subjects
}

\author{
Myriam Richelle*, Belén Sanchez, Isabelle Tavazzi, Pierre Lambelet, Karlheinz Bortlik and \\ Gary Williamson \\ Nestlé Research Center, Nestec Ltd, PO Box 44, CH-1000 Lausanne 26, Switzerland
}

(Received 18 September 2009 - Revised 6 January 2010 - Accepted 7 January 2010 - First published online 9 March 2010)

Lycopene in fruits and vegetables occurs mostly $(80-97 \%)$ in the all- $E$ configuration, whereas a considerable proportion of lycopene in the human body is present as $Z$-isomers. The $Z$-isomers offer potentially better health benefits and show improved antioxidant activity in vitro when compared with the all-E-isomer. The absorption of dietary lycopene is a complex process involving transfer of the carotenoid from the food matrix into micelles, uptake by enterocytes, packaging into chylomicrons and finally secretion into plasma. Isomerisation could take place at any of these individual steps. By exploiting in vitro and in vivo models, we traced lycopene isomerisation during absorption using various methods to mimic gastric and duodenal conditions, incorporation into mixed micelles, absorption and metabolism by various Caco- 2 cell clones, and performed a postprandial study in human subjects to identify the profile of lycopene isomers in plasma chylomicrons. We demonstrate that all-E-lycopene remains unchanged during its passage in the gastrointestinal tract, including its incorporation into mixed micelles. The key site of lycopene isomerisation is inside the intestinal cells resulting in $29 \%$ of lycopene as $Z$-isomers. Lycopene isomerisation in the various Caco-2 cell clones is consistent with that observed in human chylomicrons formed in a postprandial state. There is no selection in the release of lycopene isomers from enterocytes. Although there is a huge inter-individual variability of total lycopene absorption reported both in in vitro intestinal cell lines as well as in human chylomicrons, the lycopene isomer profile is quite similar.

Z-lycopene: Intestinal absorption: Isomerisation: Bioavailability: Carotenoids

Lycopene is an acyclic $\mathrm{C}_{40}$ non-polar carotenoid, present in several dietary sources such as tomato, watermelon, guava and apricot ${ }^{(1)}$. Although lycopene is not a provitamin A, studies have shown multiple biological activities including decreased risk of prostate cancer ${ }^{(2)}$, inhibition of cell proliferation, migration and invasion in breast, endometrial and liver carcinoma cells ${ }^{(3-8)}$, and prevention of mutagenesis and chromosome instability ${ }^{(9,10)}$. In addition, a variety of epidemiological trials indicated that high intakes of lycopenecontaining foods (primarily tomato products) or blood lycopene concentrations are associated with decreased risk of CVD and prostate cancer ${ }^{(11-15)}$.

Lycopene has eleven conjugated double bonds and each of them could be either in an $E$ or $Z$ configuration. All- $E$-lycopene is the predominant isomer in plants, representing about $80-97 \%$ of total lycopene in tomatoes and related products ${ }^{(16)}$. In human body fluids and tissues such as plasma, breast milk, prostate, testis and skin, $25-70 \%$ of lycopene is found in various $Z$ forms ${ }^{(17-24)}$. The high concentrations of $Z$-isomers in vivo triggered the hypothesis that they may be more bioavailable and/or have a different specific bioactivity. In terms of bioefficacy, Shi \& Le Maguer ${ }^{(16)}$ indicated that the biological potency of $Z$-lycopene isomers is different from that of the all-E form. Böhm et al. ${ }^{(25)}$ found that some $Z$-isomers had a stronger in vitro antioxidant activity than the all- $E$ form. For these reasons, Z-lycopene isomers are regarded as offering potentially better health benefits than the all-E-isomer.

Although $Z$-lycopene is the main component in human plasma and tissues, it is still not known if $Z$-isomers are absorbed preferentially from the food and/or if isomerisation occurs in humans. According to Tyssandier et al. ${ }^{(26)}$, lycopene appears in plasma chylomicrons mostly as all-E-lycopene after consumption of a tomato-rich meal. In contrast, Gustin et al. ${ }^{(27)}$ and Unlu et al. ${ }^{(28)}$ reported that about $40 \%$ of lycopene is present in chylomicrons as Z-lycopene isomers, indicating that lycopene isomerisation could take place during absorption. When a tomato-based meal rich in the all-E-isomer is consumed daily over a few weeks, plasma lycopene concentration increases, where $60 \%$ is as $Z$-lycopene isomers and $40 \%$ is as all- $E$-lycopene ${ }^{(29,30)}$.

In the present study, we investigated the isomerisation of lycopene during the absorption process. This evaluation has been performed at different stages of absorption: under conditions in the gastrointestinal tract using simple in vitro models such as gastric and duodenal juices, incorporation into mixed micelles and using the more sophisticated gastrointestinal model (TIM-1), under conditions found in enterocytes using Caco- 2 cells as a model of human intestinal epithelium,

Abbreviations: LC, liquid chromatography; TIM-1, computer-controlled dynamic gastrointestinal model; TRL, TAG-rich lipoproteins. 
and in vivo, in chylomicrons released during the postprandial phase in humans.

\section{Materials and methods}

\section{Tomato products}

Tomato paste, used for the TIM-1 model and for the human clinical trial, was obtained from Thomy (Vevey, Switzerland). It contained $0.0751 \mathrm{~g}$ lycopene per $100 \mathrm{~g}$. Tomato oleoresin, used for the in vitro experiments, was purchased from Indena (Milan, Italy). It was prepared by ethyl acetate extraction of tomatoes and its lycopene content was $8 \cdot 8 \mathrm{~g}$ per $100 \mathrm{~g}$. Both tomato extracts had an identical profile of lycopene isomers consisting of about $94 \%$ all- $E$ - and $5 \%$ 5-Z-isomers.

In addition to lycopene, these tomato extracts contained phytoene, phytofluene and $\beta$-carotene, but in lower amounts. Typically, in tomato paste lycopene, phytoene, phytofluene and $\beta$-carotene contributed $79,12,6$ and $3 \%$ of total carotenoids, respectively.

\section{Gastric and duodenal juices}

Gastric juice $(100 \mathrm{ml})$ was prepared using $0.3 \mathrm{~g}$ pepsin and $0.5 \mathrm{~g} \mathrm{NaCl}$ dissolved in $80 \mathrm{ml}$ distilled water; $\mathrm{pH}$ was adjusted with $1 \mathrm{M}-\mathrm{HCl}$. The solution was transferred into a volumetric flask and the volume adjusted to $100 \mathrm{ml}$. Before every experiment, gastric juice was mixed with sodium chloride $(0.5 \%)$ with a ratio 20:6 (v/v). Final $\mathrm{pH}$ was in the range of 2-4.

Duodenal juice was prepared by mixing a water solution of $4.9 \%$ porcine bile with a solution of $2.42 \%$ pancreatin (in water) and sodium phosphate buffer of $\mathrm{pH} 7.0$ (39 mM$\mathrm{NaH}_{2} \mathrm{PO}_{4}$ and $62.5 \mathrm{~mm}-\mathrm{Na}_{2} \mathrm{HPO}_{4} \mathrm{H}_{2} \mathrm{O}$ ) with a ratio of $1: 1: 7$ (by vol.). All the chemicals and digestive enzymes used to prepare the gastric and duodenal juices were from Sigma (Basel, Switzerland).

For every test on gastric or duodenal juice, $2 \mathrm{mg}$ tomato oleoresin were weighed into a dark Pyrex tube and incubated with $0.8 \mathrm{~g}$ groundnut oil under agitation at room temperature for $90 \mathrm{~min}$. After this period, $4 \mathrm{ml}$ gastric juice or $4 \mathrm{ml}$ duodenal juice or a combination of $3 \mathrm{ml}$ of each were added to the tube and incubated at $37^{\circ} \mathrm{C}$. Samples were collected after $15 \mathrm{~min}$, $30 \mathrm{~min}, 1 \mathrm{~h}$ and $2 \mathrm{~h}$ for the gastric juice and after $30 \mathrm{~min}, 1 \mathrm{~h}$ and $2 \mathrm{~h}$ for the duodenal juice and stored at $-80^{\circ} \mathrm{C}$ until analysis of their total lycopene content and their lycopene isomer profile.

\section{Mixed micelles preparation}

Artificial mixed micelles were used to screen for isomerisation within the gastrointestinal tract and also to deliver lycopene to Caco- 2 cells. Tomato oleoresin, as the lycopene source, was dissolved in dichloromethane. The preparation of mixed micelles was performed according to Sugawara et al. ${ }^{(31)}$.

\section{Dynamic gastrointestinal model}

The dynamic gastrointestinal model (TIM-1) was from TNO (Wageningen, The Netherlands) as described in detail by Minekus et al. ${ }^{(32)}$. The digestive enzymes used with this model are pepsin, porcine bile, trypsin and (-amylase from Sigma (Basel, Switzerland), Pancrex V powder from
Paines \& Byrne (Staines, Middlesex, UK) and lipase from Amano (Chipping Norton, Oxon, UK). Tomato paste $(5 \mathrm{~g})$ present in a $125 \mathrm{~g}$ portion of the standard meal was tested in duplicate. The standard meal consisted of semolina $(70 \mathrm{~g})$ cooked in $200 \mathrm{ml}$ hot water, white bread (40 g), egg whites $(60 \mathrm{~g})$, groundnut oil (40 g), natural yoghurt (125 g), sugar $(5 \mathrm{~g})$ and water $(330 \mathrm{~g})$ and was of the same composition as the one used in the human intervention study.

\section{Tissue culture}

Caco- 2 cell monolayers are a model of the human intestinal epithelium. Caco-2 cells spontaneously differentiate into polarised absorptive cell monolayers and, after differentiation, display morphological and biochemical characteristics similar to human enterocytes. This model gives reproducible values that closely correlate with in vivo data and has been used to study the molecular mechanisms involved in the absorption of carotenoids ${ }^{(33-35)}$. For the present study we used three different Caco-2 cell clones: Caco-2 SM, a generous gift of Dr Shubha Murthy (University of Iowa, USA), Caco-2 and Caco-2 HTB37 which were obtained from the America Type Culture Collection (ATCC; Rockville, MD, USA). For maintenance, Caco-2 and Caco-2 HTB37 cells were seeded at a density of $40 \times 10^{3}$ cells $/ \mathrm{cm}^{2}$, and cultured in a humidified incubator at $10 \% \mathrm{CO}_{2}$ and $37^{\circ} \mathrm{C}$ in Dulbecco's modified Eagle's medium containing $4.5 \mathrm{~g}$ glucose $/ 1,20 \%$ fetal bovine serum, $1 \%$ non-essential amino acids, gentamicin $(150 \mu \mathrm{g} / \mathrm{ml})$, fungizon $(1 \mu \mathrm{g} / \mathrm{ml})$, penicillin $(100 \mathrm{U} / \mathrm{ml})$ and streptomycin $(100 \mathrm{mg} / \mathrm{ml})$. Caco-2 SM cells were seeded at a density of $6.7 \times 10^{3}$ cells $/ \mathrm{cm}^{2}$ and cultured in a humidified incubator at $5 \% \quad \mathrm{CO}_{2}$ and $37^{\circ} \mathrm{C}$ in Dulbecco's modified Eagle's medium containing $4.5 \mathrm{~g}$ glucose $/ \mathrm{l}, 10 \%$ fetal bovine serum, gentamicin $(150 \mu \mathrm{g} / \mathrm{ml})$, penicillin $(100 \mathrm{U} / \mathrm{ml})$, streptomycin $(100 \mathrm{mg} / \mathrm{ml})$ and $2 \mathrm{mM}-\mathrm{L}-$ glutamine. The medium was changed every $2 \mathrm{~d}$. In order to obtain differentiated monolayers, Caco-2 and Caco-2 HTB37 cells were seeded at a density of $1 \times 10^{6}$ cells/well and cultured for $21 \mathrm{~d}$. Caco- $2 \mathrm{SM}$ cells were seeded at a density of $1.5 \times 10^{5}$ cells/well and cultured for $14 \mathrm{~d}$.

\section{Cellular lycopene uptake}

Medium ( $2 \mathrm{ml})$ containing lycopene-rich mixed micelles $(2 \mu \mathrm{M}$ of total lycopene) was incubated with the different Caco- 2 cell clones for periods of 2 or $6 \mathrm{~h}$. After the incubation, the supernatant fraction of the wells was collected on dry ice and stored at $-80^{\circ} \mathrm{C}$ pending analysis of total lycopene content as well as lycopene isomer profile. The cell monolayers were washed twice with PBS and cells were lysed with $5 \%$ sodium dodecyl sulfate. The lysate was also collected on dry ice and stored at $-80^{\circ} \mathrm{C}$ pending analysis of the total lycopene content and isomer profile.

\section{Human intervention study}

Subjects. There were thirty healthy men enrolled in the study. A total of twenty-seven subjects, aged 24 (SEM 1) years, completed the study. Their mean starting body weight was 70 (SEM 1) $\mathrm{kg}$ and BMI was 22.5 (SEM $0 \cdot 3) \mathrm{kg} / \mathrm{m}^{2}$. The present study was conducted according to the guidelines laid down 
in the Declaration of Helsinki and all procedures involving human subjects were approved by the ethical committee of Marseille (Marseille, France). All subjects received information on the background and design of the study and gave written informed consent before participation. They were free to withdraw from the study at any time.

Study design. Subjects were asked to refrain for $48 \mathrm{~h}$ before the postprandial test from eating tomato (fresh or sauce including ketchup and harissa), pizza, ratatouille, lasagna, pasta including tomato sauce, watermelon, pink grapefruits and guava. In addition to this dietary restriction, the subjects ate a standard meal the evening before the postprandial test consisting of green vegetables, a source of cereals (paste, bread or rice), lean meat or fish, one low-fat natural yoghurt, one fruit and one mineral water. They should have consumed this dinner in the evening between 19.00 and 20.00 hours. These recommendations were checked by the investigator on the postprandial test day. After an overnight fast, each subject consumed a standard meal (as previously described in the TIM section). This meal was consumed within $30 \mathrm{~min}$. No other food was allowed over the following $6 \mathrm{~h}$, but the subjects were allowed to drink bottled water. Blood samples were drawn before administration of the standard meal as well as at 2, 3, 4, 5 and $6 \mathrm{~h}$ post-absorption and introduced into evacuated tubes containing K-EDTA. The tubes were immediately placed into an ice-water-bath.

TAG-rich lipoprotein isolation. On the test day, plasma $(6 \mathrm{ml})$ was overlaid with $0.9 \% \mathrm{NaCl}$ solution and centrifuged for $28 \mathrm{~min}$ at $32000 \mathrm{rpm}$ at $10^{\circ} \mathrm{C}$ in an SW41Ti rotor (Beckman, Fullerton, CA, USA) in an L7 ultracentrifuge (Beckman). The upper phase containing TAG-rich lipoproteins (TRL), i.e. mainly chylomicrons with low amounts of VLDL, was collected. Immediately after recovery, TRL were divided into samples and immediately stored at $-80^{\circ} \mathrm{C}$. Total lycopene content and lycopene isomer profile were determined within $10 \mathrm{~d}$.

\section{Lycopene determination}

Total lycopene content and the profile of lycopene isomers were determined according to the method described previously by Schierle et al. ${ }^{(21)}$ for lycopene products (Fig. 1) and in vitro models, and according to the method of Ferruzzi et al. ${ }^{(36)}$ for TRL. The main lycopene isomers identified are 5-Z-, 9-Z-, 13-Z- and all-E-lycopene. Minor compounds (shown with an asterisk in Fig. 1) consisted of other Z-lycopene isomers. They were characterised as Z-lycopene with liquid chromatography (LC)-MS/MS using an Applied Biosystems APIC 4000 LC-MS/MS (Foster City, CA, USA): isocratic flow $1 \mathrm{ml} / \mathrm{min}$; declustering potential, $130 \mathrm{~V}$; $60 \mathrm{psi}(414 \mathrm{kPa}) \mathrm{N}_{2}$; capillary voltage $22 \mathrm{~V}$; vaporiser temperature, $400^{\circ} \mathrm{C}$; corona needle $5 \mu \mathrm{A}$; the fragmentation conditions used were as described by dos Anjos Ferreira et al. ${ }^{(22)}$. The peak areas of unidentified $Z$-lycopene isomers were summed and reported as $\mathrm{x}$-Z-lycopene (Table 1 ).

\section{Expression of the results}

Total lycopene is the sum of all lycopene isomers, i.e. all-Eand Z-isomers. Results of in vitro experiments are expressed as mean values and standard deviations. Results of TRL from the human intervention study are expressed as mean values with their standard errors.

\section{Results}

A simplified scheme of the absorption process of carotenoids in humans is depicted in Fig. 2. We used several models (in vitro and in vivo) to determine at which stage lycopene can undergo isomerisation: (1) within the lumen of the gastrointestinal tract; (2) incorporation into mixed micelles; (3) within the small intestine using three Caco-2 cell clones and (4) during release from enterocytes in vivo into human blood plasma (chylomicrons or TRL).

\section{Lycopene isomerisation within the gastrointestinal tract}

Lycopene in either tomato paste or tomato oleoresin consists of $94 \%$ all- $E$ - and $5 \% 5$-Z-isomers.

Step 1 in Fig. 2. We assessed lycopene isomerisation within the gastrointestinal tract using various in vitro models. Lycopene did not undergo $Z$ isomerisation in the

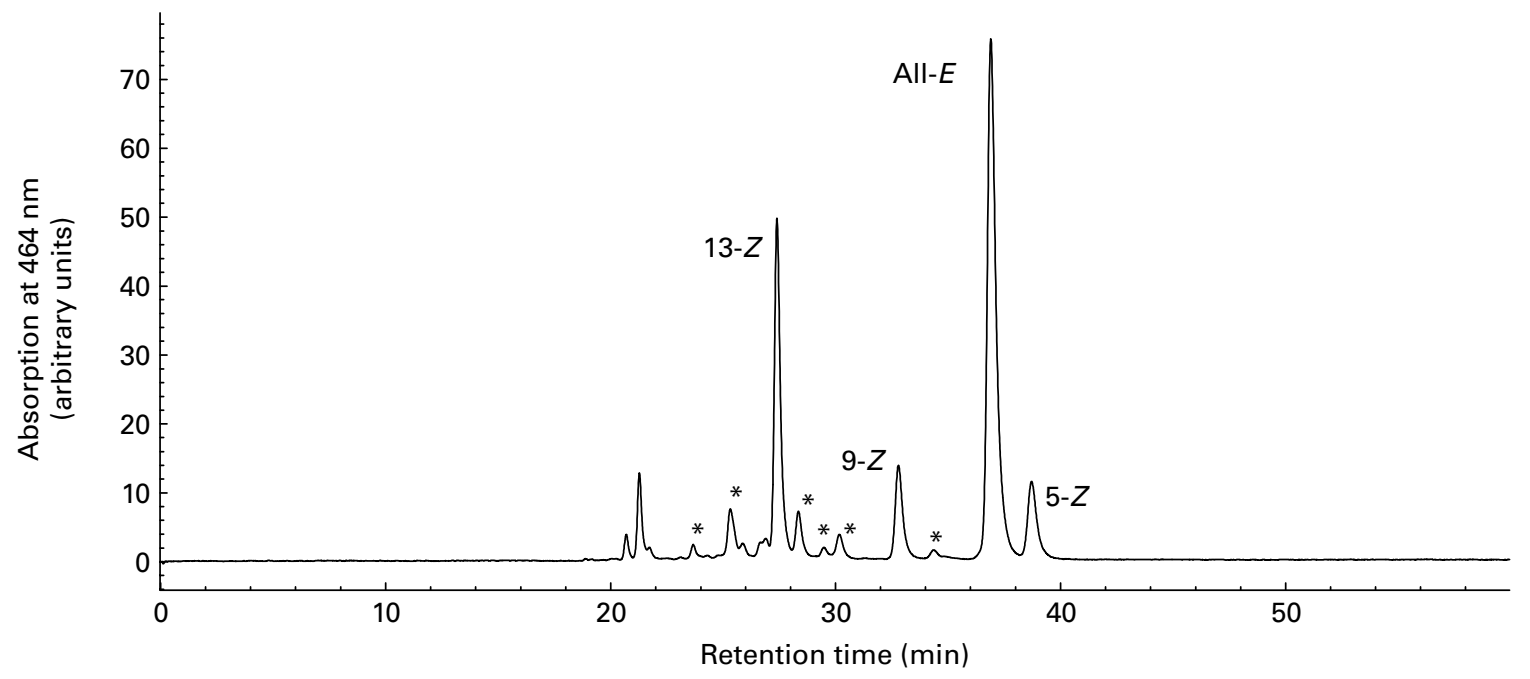

Fig. 1. Representative HPLC chromatogram of lycopene isomers. * Presence of other Z-lycopene isomers as confirmed by liquid chromatography-MS/MS. 
Table 1. Lycopene isomer profiles measured in tomato paste and tomato oleoresin, in gastrointestinal milieu (TIM-1), in mixed micelles, in Caco-2 cells as well as in human TAG-rich lipoproteins (TRL) secreted postprandially*

(Mean values and standard deviations or standard errors)

\begin{tabular}{|c|c|c|c|c|c|c|c|c|c|c|}
\hline \multirow[b]{2}{*}{ Isomer } & \multicolumn{2}{|c|}{$\begin{array}{l}\text { Tomato paste } \\
\text { and tomato } \\
\text { oleoresin }(n 4)\end{array}$} & \multicolumn{2}{|c|}{$\begin{array}{c}\text { Gastrointestinal } \\
\text { milieu (TIM-1) } \\
(n 2)\end{array}$} & \multicolumn{2}{|c|}{$\begin{array}{l}\text { Mixed micelles } \\
\qquad(n 6)\end{array}$} & \multicolumn{2}{|c|}{$\begin{array}{l}\text { Caco-2 cells } \\
\text { ( } n 4 \text { for the three } \\
\text { clones in total) }\end{array}$} & \multicolumn{2}{|c|}{$\begin{array}{l}\text { Human TRL } \\
\qquad(n 27)\end{array}$} \\
\hline & Mean & SD & Mean & SD & Mean & SD & Mean & SD & Mean & SEM \\
\hline All-E & 93.9 & 1.8 & $90 \cdot 8$ & 0.6 & 94.3 & 1.7 & $76 \cdot 7$ & 6.9 & $72 \cdot 1$ & 1.4 \\
\hline $5-Z$ & 5.0 & $1 \cdot 3$ & 4.7 & 0.1 & 4.7 & 1.1 & $12 \cdot 1$ & 1.6 & $10 \cdot 8$ & 0.7 \\
\hline $9-Z$ & 0.4 & 0.3 & 0.4 & 0.0 & 0.4 & 0.3 & 2.9 & 0.5 & 1.3 & 0.1 \\
\hline $13-Z$ & 0.5 & 0.6 & 3.4 & 0.4 & 0.5 & 0.5 & $5 \cdot 6$ & 1.2 & $7 \cdot 2$ & 0.2 \\
\hline$x-Z \dagger$ & 0.2 & 0.4 & 0.5 & 0.1 & 0.2 & 0.3 & 2.7 & 4.7 & 9.3 & 1.3 \\
\hline
\end{tabular}

${ }^{*}$ Results are expressed as percentage of total lycopene.

$\dagger \mathrm{x}-Z=$ sum of unidentified $Z$-lycopene isomers.

presence of gastric juice at $\mathrm{pH}$ values between 2 and 4 , nor in the presence of duodenal juice at $\mathrm{pH} 7$ and also not when incubated sequentially in both conditions (data not shown).

Step 2 in Fig. 2. Incorporation of lycopene into mixed micelles did not induce any degradation of lycopene (data not shown), or any change of lycopene isomer profile (Table 1).

Steps 1 and 2 in Fig. 2. In the gastrointestinal model, TIM-1, mimicking both conditions in the stomach and the small intestine, the lycopene isomer profile of the tomato product remained unchanged, confirming that lycopene isomerisation did not take place in the gastrointestinal lumen (Table 1).

\section{Lycopene isomerisation within the intestine}

Step 3 in Fig. 2. The next step in the lycopene absorption process is the transfer from the mixed micelles into human enterocytes. As a model for human enterocytes, differentiated Caco-2 cells (Caco-2, Caco-2 SM and Caco-2 HTB37) were incubated with mixed micelles containing lycopene $(2 \mu \mathrm{M})$.
The content as well as the isomer profile of lycopene present in mixed micelles were stable for at least $6 \mathrm{~h}$ under cell-culture conditions in the absence of cells.

Cells efficiently took up lycopene from mixed micelles in a time-dependent manner leading to a $13 \%$ transfer of lycopene from the mixed micelles into Caco-2 or Caco-2 SM cells at the end of the $6 \mathrm{~h}$ incubation, while this transfer was about four times lower (3\%) for the Caco-2 HTB37 clone. The intracellular lycopene isomer profile was similar in the three cell clones and consisted of a significantly higher proportion of $Z$-isomers than in the starting material: $5-Z$ (12.1 (SD $1.6) \%$ total lycopene) $>13-Z \quad(5.6 \quad$ (SD 1.2$) \%$ total lycopene) $>9-Z(2.9$ (SD 0.5$) \%$ total lycopene) $>x-Z(2 \cdot 7$ (SD 4.7$) \%$ total lycopene). The lycopene isomer profile in the cells was similar after 2 and $6 \mathrm{~h}$ incubation (data not shown), even though the total lycopene content was lower after $2 \mathrm{~h}$. The absence of $Z$-lycopene isomers in the incubation medium indicates that lycopene isomerisation took place within the cells.

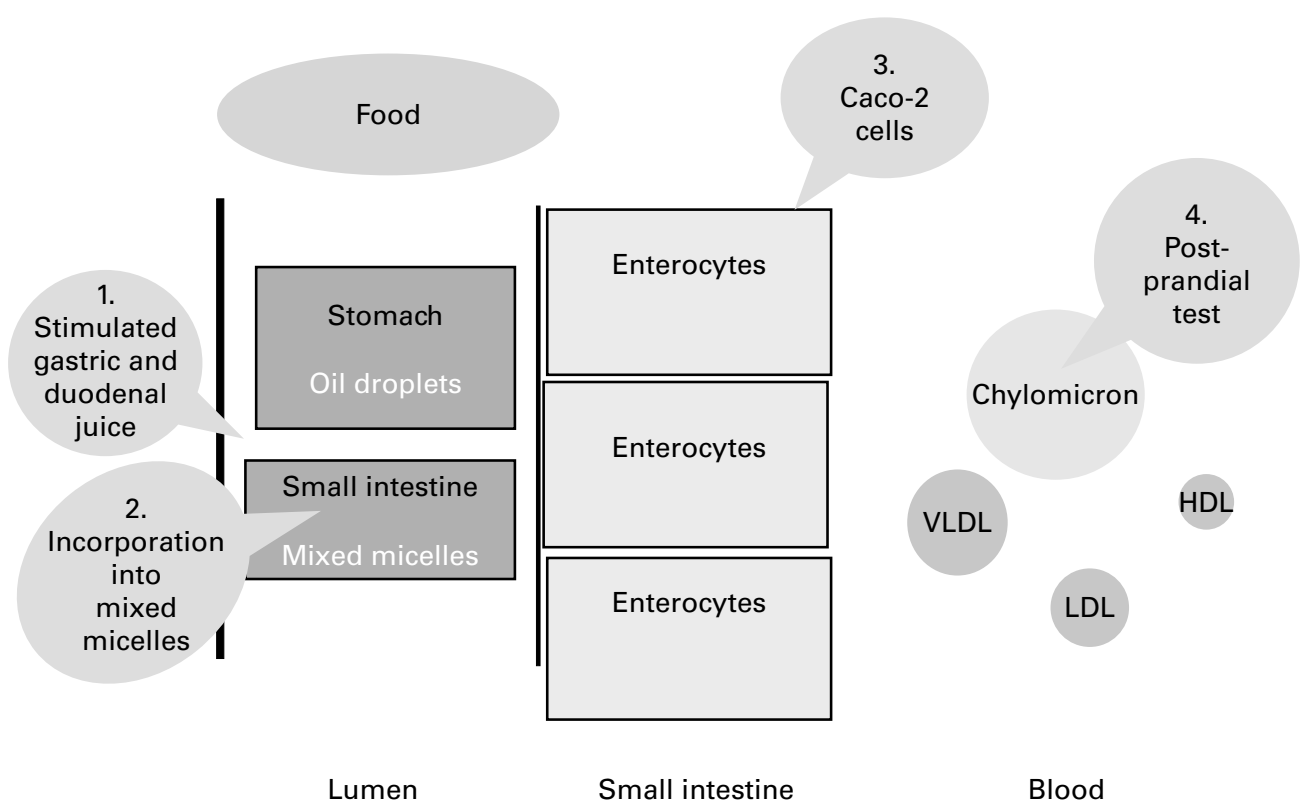

Fig. 2. Simplified scheme of the absorption of lycopene in human subjects. The in vitro and in vivo model systems mimicking different stages of lycopene digestion and absorption that were used during the work are indicated as 1-4. 


\section{Lycopene isomerisation during absorption in humans}

Step 1 to step 4 in Fig. 2. We performed a postprandial test in healthy males to allow characterisation of the lycopene appearing in intestinal secreted lipoproteins, i.e. chylomicrons. Subjects consumed a standard meal containing lycopene present in tomato paste, i.e. providing mainly all-E-lycopene (Table 1). This standard meal contained $40 \mathrm{~g}$ groundnut oil to ensure that subjects would secrete chylomicrons into the blood circulation. Consumption of the standard meal led to a marked production of chylomicron particles in TRL as characterised by the increase of plasma TAG concentration (Fig. 3(a)). Lycopene was efficiently absorbed and secreted in chylomicrons as shown by the rise of TRL-lycopene concentration (Fig. 3(b)). The profile of lycopene isomers appearing in TRL consisted of $29 \%$ of Z-lycopene isomers with the proportion decreasing in the following order: $5-Z$ (10.8 (SD 0.7) \%); $\mathrm{x}-Z$ (9.3 (SD 1.3) \%); 13-Z (7.2 (SD 0.2) $\%)$; $9-Z(1.3(\operatorname{SD} 0.1) \%)$. This profile of $Z$-lycopene isomers was similar between 2 and $6 \mathrm{~h}$ post-absorption. In contrast to the 23-fold inter-individual variation observed for total lycopene bioavailability, the proportion of Z-lycopene isomers in TRL only showed an inter-subject variation of 4 (Fig. 4). This indicates that 'low' and 'high' lycopene absorbers ${ }^{(19-21)}$ exhibit quite similar ability to isomerise lycopene.

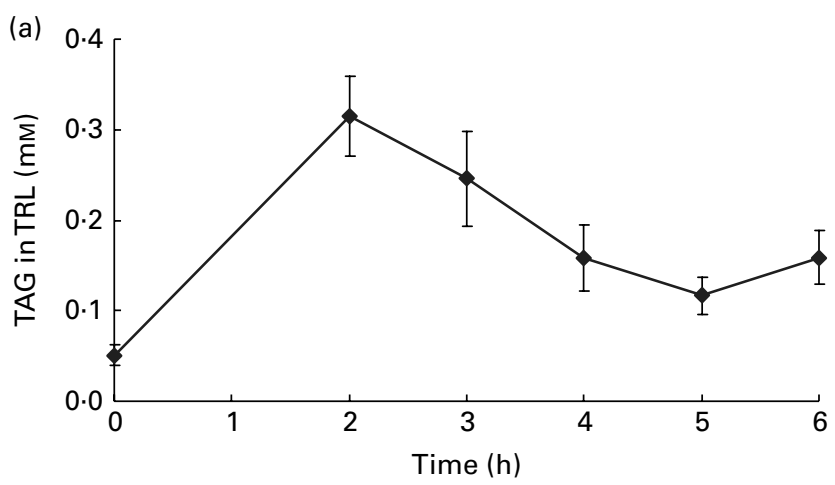

(b)

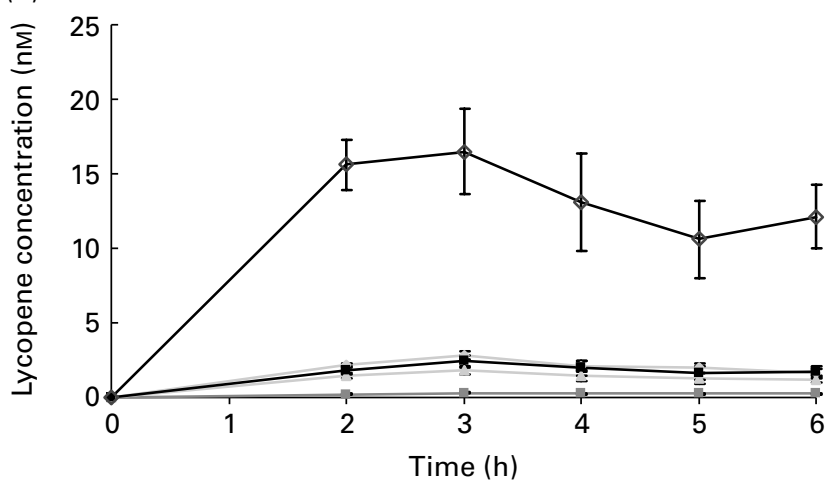

Fig. 3. TAG (a) and lycopene isomer (b) concentrations in TAG-rich lipoproteins (TRL)-containing chylomicrons of subjects having consumed a standard meal. Results are expressed in mM for TAG and in nM for lycopene. $(-\diamond-)$, All-E-lycopene; (- $(--)$ ), 5-Z-lycopene; (- $-Z-), \quad$ 9-Z-lycopene; $(---)$, 13-Z-lycopene; $(-\mathbf{-}-)$, sum of unidentified Z-lycopene isomers. Values are means ( $n 27)$, with standard errors represented by vertical bars.

\section{Discussion}

The absorption of lycopene requires lycopene partitioning into bile salt micelles during small intestine digestion, uptake across the brush-border membrane of enterocytes and incorporation into chylomicron particles for secretion into lymph (Fig. 2).

Lycopene isomerisation did not take place in the gastrointestinal lumen either in the stomach, in the duodenum, or during transfer into mixed micelles, as assessed with various in vitro models. In contrast, all- $E$-lycopene was isomerised into various $Z$-lycopene isomers when in contact with various clones of Caco-2 cells. Lycopene absorption with a meal led to the secretion of chylomicrons present in TRL containing about $29 \%$ of lycopene as Z-lycopene isomers. The proportion of individual lycopene isomers in Caco- 2 cell monolayers, and in human TRL, was quite consistent, and decreased in the following order: $5-Z>13-Z=\mathrm{x}-Z>9-Z$. The presence of 9-Z-, $13-Z$ - and $x-Z$-isomers indicates lycopene isomerisation rather than preferential uptake of $Z$-lycopene, since these lycopene isomers were absent in the test lycopene preparations which contained about $94 \%$ all- $E$ - and about $5 \%$ 5-Z-lycopene. However, this does not exclude a preferential uptake of $5-Z$ lycopene by cells, since its proportion was higher in the Caco-2 cell monolayers and TRL than in the lycopene preparation.

Given that isomerisation of all- $E$-lycopene into $Z$-isomers is promoted by contact with acids ${ }^{(37)}$, our first goal was to assess whether there was any isomerisation of lycopene in the acidic environment of the stomach and the small intestine. Our finding showing an absence of lycopene isomerisation in the stomach is in agreement with results obtained in vitro ${ }^{(38)}$ and in healthy subjects ${ }^{(26)}$. However, they disagree with in vitro results showing an isomerisation of lycopene that has been reported in vitro in a 'gastric milieu' set at $\mathrm{pH}$ $1 \cdot 6^{(26,39)}$. This discrepancy might be due to the use of a low $\mathrm{pH}$ in this in vitro model, which mimics the stomach $\mathrm{pH}$ in the fasting stage only. Indeed, the stomach $\mathrm{pH}$, which is about 1.8 in the fasting state, sharply increases to 5.4-6.2 after intake of a meal, and then continuously decreases to reach $1.8-2.9$ after $3 \mathrm{~h}$ digestion. The duodenal $\mathrm{pH}$, which is about 5 in the fasting state, increases to $\mathrm{pH} \mathrm{6.1-6.6} \mathrm{after}$ intake of a meal and remains constant during digestion. In the present results, we did not observe isomerisation of lycopene in the in vitro model mimicking this duodenal condition. In the gastrointestinal lumen, the final step before absorption is the transfer of lycopene into mixed micelles. The isomer profile of lycopene in the mixed micelles was similar to the one of the tomato product, which indicates no lycopene isomerisation, but also no preferential transfer of $Z$-lycopene (in our particular case, 5-Z-lycopene). This is in disagreement with results of Boileau et al. ${ }^{(40)}$ showing a higher incorporation of Z-lycopene into mixed micelles than the all- $E$ counterpart. Using the more sophisticated TIM-1 model, which is an in vitro model that allows the closest simulation of in vivo dynamic physiological processes occurring in the lumen of the stomach currently available, we confirm that lycopene does not undergo isomerisation in the gastrointestinal tract. These results are in agreement with those recently reported by Blanquet-Diot et al. ${ }^{(41)}$. Although the main parameters of digestion, such as $\mathrm{pH}$, body temperature, peristaltic mixing and transport, gastric, biliary and pancreatic secretions 

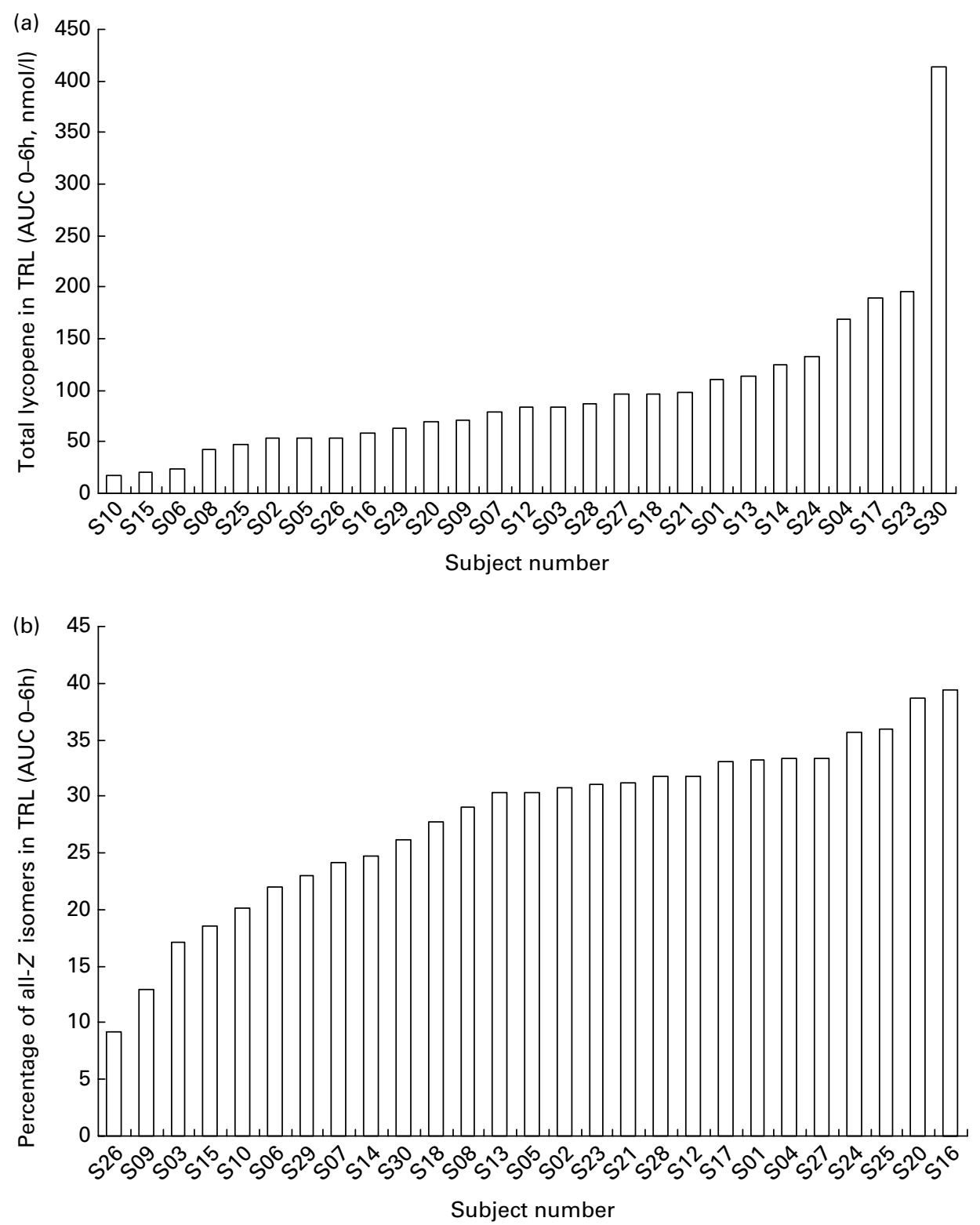

Fig. 4. Inter-individual variation: total lycopene concentration (a) and percentage of all-Z-lycopene isomers (b) in TAG-rich lipoproteins (TRL) of each individual subject having consumed a standard meal containing lycopene ( $n$ 27). Results are expressed in nM for total lycopene and as percentage of total lycopene for the all-Z-lycopene isomers. The all-Z-lycopene isomers consist of the sum of 5-Z-, 9-Z-, 13-Z- and unidentified $Z$-lycopene isomers. AUC, area under the curve.

and passive absorption of small molecules and water are reproduced, the actual limitations of the TIM-1 model reside in the absence of a cellular system and a feedback mechanism.

To mimic enterocyte transport and metabolism, we used three clones of Caco- 2 cells. Cell culture condition did not affect either lycopene content or isomer profile. Lycopene uptake by either Caco-2 or Caco-2 SM was similar, but markedly lower by Caco-2 HTB37 cells. However, lycopene isomerised in all these three cell clones and the profile of lycopene isomers were similar. The results in Caco- 2 cells matched in vivo results. Lycopene appearing in chylomicrons (TRL) and in Caco- 2 cells consisted of 29 and $24 \%$, respectively, as a mixture of Z-lycopene isomers. This is in agreement with results described by Gustin et al. ${ }^{(27)}$ and Unlu et al. ${ }^{(28)}$. In contrast, Tyssandier et al. ${ }^{(26)}$ did not detect
Z-lycopene isomers in chylomicrons isolated from plasma from most individuals. Although a large inter-individual variation of lycopene bioavailability is in agreement with data reported by several authors ${ }^{(42-44)}$ and is characteristic of the presence of low and high absorbers in the population, a low inter-individual variation of the proportion of $Z$ - to $E$-lycopene is noteworthy. These results indicate that whatever the lycopene absorption efficiency, lycopene isomerisation is quite similar and suggest that the factors participating in lycopene absorption are different from those involved in lycopene isomerisation.

In most human tissues, more than $50 \%$ of the lycopene is a mixture of $Z$-isomers ${ }^{(23,28,44,45)}$. The major $Z$-isomers in plasma were, in decreasing order of abundance: $5-Z>13-Z$ $>9-Z$. In humans, the $Z$-lycopene concentration is high in 
the liver, adrenal glands, testes, skin and prostate ${ }^{(18,46,47)}$. The $29 \%$ Z-lycopene in human chylomicrons present in TRL suggests that, in the human body, additional mechanisms are involved which increase markedly the proportion of $Z$-lycopene by processes such as isomerisation, preferential uptake or reduced catabolism of the Z-lycopene isomers. The high proportion of $Z$-lycopene isomers in human tissues could conceivably be a conversion to a more biologically effective form. It is not feasible to compare the efficacy of $Z$ - and $E$-lycopene in vivo, owing to the metabolic conversion of one form to another. However, Böhm et al. ${ }^{(25)}$ demonstrated that $Z$-lycopene isomers exhibit higher antioxidant capacity than their all- $E$ counterpart in vitro. Thus it is tempting to speculate that the $E$ - to $Z$-lycopene conversion in vivo is a metabolic activation of this carotenoid.

\section{Acknowledgements}

We thank Dr Karen Cooper for organising the in vitro gastrointestinal TIM-1 trials at TNO and Dr Francesca Giuffrida for the LC-MS/MS identification of the $Z$-isomers of lycopene.

The present study was funded in full by the Nestlé Research Center, Lausanne, Switzerland.

M. R., B. S., P. L., K. B. and G. W. conceived of and designed the present study. B. S., I. T., P. L. and K. B. achieved the design and production of formulations of the lycopene products. M. R. coordinated the trial and supervised the analytic aspects. B. S., I. T., P. L. and K. B. contributed to the development of analytic methods, lycopene analysis and data collection. M. R. wrote the manuscript, and all authors were involved in interpreting the results and in critical revision of the paper.

No author has any advisory board affiliations. There is no conflict of interest.

\section{References}

1. Boileau TWM, Boileau AC \& Erdmea JW Jr (2002) Bioavailability of all-trans and cis-isomers of lycopene. Exp Biol Med 227, 914-919.

2. Gann PH, Ma J, Giovanucci E, et al. (1999) Lower prostate cancer risk in men with elevated plasma lycopene levels: results of a prospective analysis. Cancer Res 59, 1225-1230.

3. Blaner WS \& Olson JA (1994) Retinol and retinoic acid metabolism. In The Retinoids: Biology, Chemistry and Medicine, 2nd ed., pp. 229-255 [MB Sporin, AB Roberts and S Goodman, editors]. New York: Raven Press.

4. Chalabi N, Delort L, Le Corre L, et al. (2006) Gene signature of breast cancer cell lines treated with lycopene. Pharmacogenomics 7, 663-672.

5. Chalabi N, Le Corre L, Maurizis JC, et al. (2004) The effect of lycopene on the proliferation of human breast cells and BRCA1 and BRCA2 gene expression. Eur J Cancer 40, 1769-1775.

6. Chalabi N, Satih S, Delort L, et al. (2007) Expression profiling by whole genome microarray hybridization reveals differential gene expression in breast cancer cell lines after lycopene exposure. Biochim Biophys Acta 1796, 124-130.

7. Huang CS, Shih MK, Chuang CH, et al. (2005) Lycopene inhibits cell migration and invasion and upregulates $\mathrm{Nm} 23-\mathrm{H} 1$ in a highly invasive hepatocarcinoma, SH-Hep-1 cells. J Nutr 135, 2119-2123.

8. Nahum A, Zeller L, Danilenko M, et al. (2006) Lycopene inhibition of IGF-induced cancer cell growth depends on the level of cyclin D1. Eur J Nutr 45, 275-282.
9. Liu C, Russell RM \& Wang XD (2006) Lycopene supplementation prevents smoke induced changes in p53 phosphorylation, cell proliferation, and apoptosis in the gastric mucosa of ferrets. J Nutr 136, 106-111.

10. Russell RM (1998) Physiological and clinical significance of carotenoids. Int $J$ Vitam Nutr Res 68, 349-353.

11. Rao AV (2002) Lycopene, tomatoes, and the prevention of coronary heart disease. Exp Biol Med (Maywood) 227, 908-913.

12. Levy J, Bosin E, Feldman B, et al. (1995) Lycopene is a more potent inhibitor of human cancer cell proliferation than either $\alpha$-carotene or $\beta$-carotene. Nutr Cancer 24, 257-266.

13. Giovannucci E, Ascherio A, Rimm EB, et al. (1995) Intake of carotenoids and retinol in relation to risk of prostate cancer. J Natl Cancer Inst 87, 1767-1776.

14. Etminan M, Takkouche B \& Caamaño-Isorna F (2004) The role of tomato products and lycopene in the prevention of prostate cancer: a meta-analysis of observational studies. Cancer Epidemiol Biomark Prevent 13, 340-345.

15. Erdman JW Jr, Ford NA \& Lindshield BL (2009) Are the health attributes of lycopene related to its antioxidant function? Arch Biochem Biophys 483, 229-235.

16. Shi J \& Le Maguer M (2000) Lycopene in tomatoes: chemical and physical properties affected by food processing. Crit Rev Food Sci Nutr 40, 1-42.

17. Alien CM, Smith AM, Clinton SK, et al. (2002) Tomato consumption increases lycopene isomer concentrations in breast milk and plasma of lactating women. J Am Diet Assoc 102, 1257-1262.

18. Clinton SK, Emenhiser C, Schwartz SJ, et al. (1996) Cis-trans lycopene isomers, carotenoids and retinol in the human prostate. Cancer Epidemiol Biomarkers Prev 5, 823-833.

19. Hadley CW, Clinton SK \& Schwartz SJ (2003) The consumption of processed tomato products enhances plasma lycopene concentrations in association with a reduced lipoprotein sensitivity to oxidative damage. J Nutr 133, 727-732.

20. Holloway DE, Yang M, Paganga G, et al. (2000) Isomerization of dietary lycopene during assimilation and transport in plasma. Free Radic Res 32, 93-102.

21. Schierle J, Bretzel W, Bühler I, et al. (1997) Content and isomeric ratio of lycopene in food and human plasma. Food Chem 59, 459-465.

22. dos Anjos Ferreira AL, Yeum K-J, Russell RM, et al. (2004) Enzymatic and oxidative metabolites of lycopene. J Nutr Biochem 15, 493-502.

23. Stahl W \& Sies H (1992) Uptake of lycopene and its geometrical isomers is greater from heat-processed than from unprocessed tomato juice in humans. J Nutr 122, 2161-2166.

24. Wu K, Schwartz SJ, Platz EA, et al. (2003) Variations in plasma lycopene and specific isomers over time in a cohort of U.S. men. J Nutr 133, 1930-1936.

25. Böhm V, Puspitasari-Nienaber NL, Ferruzzi MG, et al. (2002) Trolox equivalent antioxidant capacity of different geometrical isomers of $\alpha$-carotene, $\beta$-carotene, lycopene, and zeaxanthin. J Agric Food Chem 50, 221-226.

26. Tyssandier V, Reboul E, Dumas JF, et al. (2003) Processing of vegetable-borne carotenoids in the human stomach and duodenum. Am J Physiol Gastrointest Liver Physiol 284, G913-G923.

27. Gustin DM, Rodvold KA, Sosman JA, et al. (2004) Single-dose pharmacokinetic study of lycopene delivered in a well-defined food-based lycopene delivery system (tomato paste oil mixture) in healthy adult male subjects. Cancer Epidemiol Biomarkers Prev 13, 850-860.

28. Unlu NZ, Bohn T, Francis DM, et al. (2007) Lycopene from heat-induced $c i s$-isomer-rich tomato sauce is more bioavailable than from all-trans-rich tomato sauce in human subjects. $\mathrm{Br} \mathrm{J}$ Nutr 98, 140-146. 
29. Richelle M, Bortlik K, Liardet S, et al. (2002) A food-based formulation provides lycopene with the same bioavailability to humans as that from tomato paste. J Nutr 132, 404-408.

30. Burri BJ, Chapman MH, Neidlinger TR, et al. (2009) Tangerine tomatoes increase total and tetra-cis-lycopene isomer concentrations more than red tomatoes in healthy adult humans. Int $J$ Food Sci Nutr 60, 1-16.

31. Sugawara T, Kushiro M, Zhang H, et al. (2001) Lysophosphatidylcholine enhances carotenoid uptake from mixed micelles by Caco-2 human intestinal cells. J Nutr 131, 2921-2927.

32. Minekus M, Marteau P, Havenaar R, et al. (1995) A multicompartmental dynamic computer-controlled model simulating the stomach and small intestine. Altern Lab Anim 23, 197-209.

33. Reboul E, Abou L, Mikail C, et al. (2005) Lutein transport by Caco-2 TC-7 cells occurs partly by a facilicitated process involving the scavenger receptor class B type I (SR-BI). Biochem $J$ 387, 455-461.

34. During A, Dawson HD \& Harrison EH (2005) Carotenoid transport is decreased and expression of the lipid transporters SR-BI, NPC1L1, and ABCA1 is downregulated in Caco-2 cells treated with ezetimibe. J Nutr 135, 2305-2312.

35. Moussa M, Landrier J-F, Reboul E, et al. (2008) Lycopene absorption in human intestinal cells and in mice involves scavenger receptor class B type I but no niemann-pick C1-like 1. J Nutr 138, 1432-1436.

36. Ferruzzi MG, Nguyen ML, Sander LC, et al. (2001) Analysis of lycopene geometrical isomers in biological microsamples by liquid chromatography with coulometric array detection. J Chromatogr B Biomed Sci Appl 760, 289-299.

37. Rodriguez-Amaya DB (1999) Changes in carotenoids during processing and storage foods. Arch Latinoam Nutr 49, Suppl. 3, $38 \mathrm{~S}-47 \mathrm{~S}$.
38. Failla ML, Chitchumroonchokchai C \& Ishida BK (2008) In vitro micellarization and intestinal cell uptake of cis-isomers of lycopene exceed those of all-trans lycopene. J Nutr 138, 482-486.

39. Moraru C \& Lee T-C (2005) Kinetic studies of lycopene isomerization in a tributyrin model system at gastric $\mathrm{pH}$. $\mathrm{J} \mathrm{Agr}$ Food Chem 53, 8997-9004.

40. Boileau AC, Merchen NR, Wasson K, et al. (1999) Cis-lycopene is more bioavailable than trans-lycopene in vitro and in vivo in lymph-cannulated ferrets. J Nutr 129, 1176-1181.

41. Blanquet-Diot S, Soufi M, Rambeau M, et al. (2009) Digestive stability of xanthophylls exceeds that of carotenes as studied in a dynamic in vitro gastrointestinal system. $J$ Nutr 139, 876-883.

42. Borel P, Grolier P, Mekki N, et al. (1998) Low and high responders to pharmacological doses of $\beta$-carotene: proportion in the population, mechanisms involved and consequences on $\beta$-carotene metabolism. J Lipid Res 39, 2250-2260.

43. Cardinault N, Tyssandier V, Grolier P, et al. (2003) Comparison of the postprandial chylomicron carotenoid responses in young and older subjects. Eur J Nutr 42, 315-323.

44. O'Neill ME \& Thurnham DI (1998) Intestinal absorption of $\beta$-carotene, lycopene and lutein in men and women following a standard meal: response curves in the triacylglycerol-rich lipoprotein fraction. Br J Nutr 79, 149-159.

45. Stahl W, Schwarz W, Sundquist AR, et al. (1992) Cis-trans isomers of lycopene and $\beta$ carotene in human serum and tissues. Arch Biochem Biophys 294, 173-177.

46. Clinton SK (1998) Lycopene: chemistry, biology, and implications for human health and disease. Nutr Rev 56, 35-51.

47. Khachik F, Carvalho L, Bernstein PS, et al. (2002) Chemistry, distribution, and metabolism of tomato carotenoids and their impact on human health. Exp Biol Med (Maywood) 227, $845-851$ 